$7-8-2020$

\title{
Supporting faculty through an open education and affordability gratitude campaign
}

Mandi Goodsett

Cleveland State University, a.goodsett@csuohio.edu

Follow this and additional works at: https://engagedscholarship.csuohio.edu/msl_facpub

Part of the Library and Information Science Commons

How does access to this work benefit you? Let us know!

\section{Publisher's Statement}

This post-print manuscript is shared under a Creative Commons Attribution Non-commercial International Licence 4.0 (CC BY-NC 4.0). To reuse this work for commercial purposes, permission should be sought by contacting permissions@emeraldinsight.com. Commercial usage includes but is not limited to: o Copying or downloading manuscript for further distribution for a fee; o Any use of the manuscript in conjunction with advertising; o Any use of the manuscript for promotional purposes by for-profit organisations; o Any use that would confer monetary reward, commercial gain or commercial exploitation.

\section{Original Citation}

Goodsett, M. (2020), "Supporting faculty through an open education and affordability gratitude campaign", Reference Services Review, Vol. 48, No. 3. https://doi.org/10.1108/RSR-03-2020-0008

\section{Repository Citation}

Goodsett, Mandi, "Supporting faculty through an open education and affordability gratitude campaign" (2020). Michael Schwartz Library Publications. 169.

https://engagedscholarship.csuohio.edu/msl_facpub/169

This Article is brought to you for free and open access by the Michael Schwartz Library at EngagedScholarship@CSU. It has been accepted for inclusion in Michael Schwartz Library Publications by an authorized administrator of EngagedScholarship@CSU. For more information, please contact library.es@csuohio.edu. 
Supporting faculty through an open education and affordability gratitude campaign

\begin{tabular}{|r|l|}
\hline Journal: & Reference Services Review \\
\hline Manuscript ID & RSR-03-2020-0008.R2 \\
\hline Manuscript Type: & Original Article \\
\hline Keywords: & $\begin{array}{l}\text { open education, affordability, outreach, faculty, Collaboration, social } \\
\text { proof }\end{array}$ \\
\hline
\end{tabular}

\section{SCHOLARONE \\ Manuscripts}


Using a gratitude campaign to encourage faculty support of open education and affordability

\begin{abstract}
Purpose

The purpose of this case study is to demonstrate how an academic library can use a library-led, public, positive, and broad faculty gratitude campaign to help a campus embrace a culture of open education.
\end{abstract}

\title{
Design/methodology/approach
}

Using a literature review of faculty outreach efforts in the area of open education, as well as an examination of the psychology of persuasion, this library developed a gratitude campaign that consisted of a faculty video, letters from the Provost, signed cards from students, door hangers, and the delivery of swag bags to faculty offices.

\begin{abstract}
Findings
While it is challenging to assess how much an initiative may have changed campus culture, initial responses to the gratitude campaign have been overwhelmingly positive. In addition, it cost little or nothing to develop the campaign and materials can be reused in future events and initiatives.
\end{abstract}

\section{Practical implications}

Changing campus culture, maintaining momentum in a program with limited funding, and reaching reluctant faculty are all challenges for open education initiatives. Initiating a gratitude 
campaign can begin to address all of these by being public, positive, and inclusive. This case study describes how a campus could adopt any or all of the gratitude campaign strategies, and it includes openly licensed examples, templates, and models for readers to use.

\section{Originality/value}

Open education and affordability efforts that use presentations, grant programs, and awards are common on academic campuses. However, when funding is tight or these efforts fail to reach new audiences, a gratitude campaign can make inroads where these traditional efforts are limited.

\section{Keywords}

open education, affordability, outreach, faculty, gratitude, video, social proof, persuasion, library, collaboration

Paper Type - Case study

\section{Introduction}

"Give thanks for a little and you will find a lot." - Hausa Proverb

Many academic librarians are interested in promoting open education and affordability on their campuses. Evidence of the negative impact of textbook costs on student academic outcomes is mounting, often resulting in "student survivalism," which Thompson et al. describe as "opting out of some classes and majors and often delaying or declining to purchase assigned readings, setting [students] back by weeks of study or simply leaving them hopelessly behind their 
wealthier peers" (2017). Since 2000, cost barriers alone have prevented 2.4 million low- and middle-income students in the United States from completing college (U.S. Advisory Committee on Student Financial Assistance, 2006). While textbook and other coursework costs only comprise one part of the financial hurdle for post-secondary students, these costs are often surprising to students, may not be covered by financial aid, and have a disproportionate impact on student success. Between 1977 and 2015, consumer prices for textbooks have increased over 1,000\% (Popken, 2015). In 2018, the high cost of textbooks caused 64\% of students to decide not to purchase one or more of their required textbooks, $43 \%$ to take fewer courses, $23 \%$ to drop a course, and $17 \%$ to fail a course (Florida Virtual Campus, 2019). Even more troubling, evidence shows that the impact of textbook costs is greater for Pell-eligible and part-time students (Colvard et al., 2018).

The disproportionate impact of course material costs on student success has led many higher education institutions to commit to reducing textbook costs. However, building an affordability initiative can be challenging, especially when faculty are hesitant or skeptical about switching to an open, free, or low-cost textbook alternative. Even when some faculty are enthusiastic and motivated to contribute significant time and energy to moving toward open education, a program's momentum can be slowed by resistance to the initiative by other faculty.

One solution to this problem is to publicly encourage and reward "early adopter" faculty for their contributions to affordability. This article will provide a literature review of encouragement strategies used at various libraries, and it will also present several methods employed by the author's library, including featuring faculty in videos, distributing "thank you" door hangers, thanking faculty in social media posts, and giving affordability advocates swag bags. Many libraries already have developed larger-scale methods of motivating or compensating 
faculty, such as through grants and awards, so emphasis in the present article will be on opportunities to show gratitude when additional funding is not available. The strategies described will also attempt to be as inclusive as possible; for example, including faculty who use library resources or who have completely eliminated the use of a textbook and are often overlooked by grant programs. Showing gratitude to these faculty is also a chance to celebrate the library services that help all of our faculty and students on a regular basis.

\section{Faculty Outreach and Open Education}

Jensen and West (2015) define open education as "a philosophy, a pedagogical shift, and a movement that works to improve educational experiences through adopting learning materials that aren't locked down by restrictive copyright laws." The materials that drive open education are called open educational resources (OERs), which are openly-licensed materials used for teaching that allow for what David Wiley has called the "5R activities" (Wiley n.d). The five permissions that Wiley describes are the ability to retain, revise, remix, reuse, and redistribute the work (Wiley n.d.). These permissions allow faculty and students to engage in many activities that would normally be restricted by copyright, opening the door for faculty to customize their courses in ways that improve student learning.

At its core, the open education movement is not just about OERs, but about freeing and improving the educational experience (Paskevicius 2017). This shift involves, as Jensen and West assert, pedagogical changes beyond just the type of materials that are assigned in a course; open education encourages improving student learning by considering the course materials and the materials that students create in the process of learning. Nascimbeni and Burgos describe an open educator as exhibiting the following actions: transparently sharing teaching ideas and 
resources with others, using OERs in instruction, implementing open pedagogy practices that engage students, and adopting open assessment activities (2016). To make the transformation in pedagogy required by open education, a shift in the culture on our campuses and in higher education is necessary.

A culture shift to the use of OERs is difficult in part because faculty face barriers to adoption that are complicated and challenging to overcome. First, while it is becoming more common for faculty to have heard of OERs, a lack of faculty awareness or understanding can prevent a culture shift (Babson Report 2019). When faculty learn about open education, even if they become interested, they may need training in order to find and use OERs, especially when they are interested in remixing projects that require technological skill (Amiel 2013). If they perceive that training and support is not available, they may choose not to complete or attempt an OER project (Amiel 2013). Even if faculty are interested and training is available, one particularly substantial barrier is a lack of time (Lieberman 2018). Faculty must use their time wisely, especially those who are on the tenure track and, unfortunately, the creation of open materials is not often considered in tenure decisions. These and other challenges give faculty legitimate pause when it comes to adopting the practices of an open educator (Nascimbeni and Burgos 2016).

Libraries have frequently been central to open education efforts. Librarians are often OER advocates, OER finders, and OER publishers, leading the way on their campuses. Librarians fill this role successfully because they have the skills to find high-quality course materials; knowledge of copyright and, to some extent, publishing; training skills and resources; and a central campus platform to advocate for the sweeping change necessary to move to open (Cassidy et al., 2015; Jensen and West, 2015). In addition, and perhaps most importantly, open 
education resonates with many of the values that librarians have adopted as professionals, such as access to information, lifelong learning, and academic freedom.

Librarians reach out to faculty to encourage the adoption and creation of open textbooks in a number of ways. One central role that librarians play is in helping faculty find appropriate open course materials. For example, at Utah State University, librarians offer a service of reviewing faculty syllabi and helping them find OERs and library-licensed resources to meet their course objectives (Davis et al., 2016). Librarians also can play a role in making OERs more discoverable and curating the materials developed at their own institution (Okamoto, 2013). This often means sharing OERs via an institutional repository or other platform and providing robust metadata in the process (Mitchell and Chu, 2014). Martin emphasizes that academic librarians have a responsibility to manage and understand collections of free and openly licensed content in order to successfully meet the needs of patrons (2010).

Librarians can also play an important outreach role by providing professional development and training programs for faculty. Events can be centered around Open Access Week or Open Education Week, or consist of regular workshops (Salem, 2017). Dean (2018) describes her programming efforts at Clemson University, which include an informational pizza party for students, workshops for faculty, visits to departmental meetings, and drop-in information sessions about her library's grant program. Rigling and Cross' (2018) textbook affordability program at North Carolina State University offers Open Access Week pop-up interviews with students, whiteboards with questions for students, and a workshop series about open access and open education. These outreach offerings both train faculty and advocate for open education, often to a captive audience. 
Offering faculty incentive programs through textbook adoption or creation grants has become a popular strategy for encouraging OER adoption and creation, and these programs have often met with success. Effective programs can be found at the University of Massachusetts at Amherst (Smith 2018), the State University of New York (SUNY) system (Pitcher, 2014), the Emory Open Education Initiative (Emory Scholarly Communication Office, n.d.), the University of California at Los Angeles' Affordable Textbook Initiative (Celik and Peck, 2016), the University of Minnesota's Partnership for Affordable Content (Jensen, 2018), Oregon State University Libraries and Press open textbook program (Sutton and Chadwell, 2014), and Ohio University's Alt-Textbook Initiative (Salem, 2017). These programs vary in their scale and objectives (i.e., textbook adoption vs. creation), but all have found success in financially supporting faculty to make the transition to openly licensed course material.

One of the most valuable outcomes of faculty outreach programs is the development of faculty champions who can advocate for open education to their peers (Salem, 2017). Helping faculty find materials, training them about open education, and providing grants or awards to aid in their adoption of open material all lead faculty to become part of a larger initiative and, also, potentially, faculty champions who will spread the word to their colleagues.

These faculty outreach strategies can be especially effective in engaging early adopters. However, for institutions that are ready to move beyond engaging early adopters and do not have the resources to offer or increase these options, strategically promoting faculty work already being done can capitalize on the existing momentum on those campuses. While there are plenty of case studies describing faculty outreach efforts that require funding or significant investments in time, there are few to date that outline the smaller projects that campuses can undertake for 
little or no cost. In addition, few studies draw a connection between their faculty outreach efforts and psychological concepts that strengthen their approach.

\section{The Psychology of Public Gratitude}

Many faculty choose not to use an open textbook for reasons that are outside of their (and their campus') control. For example, for many there is still no open alternative that meets their curricular needs, and for others the commercial textbook they use is uniquely suited to their course and not very expensive. In addition, the work required to adopt or create open educational resources may not be recognized in the promotion and tenure process, compromising the return on investment. Many of these faculty have chosen to take action to aid students in reducing textbook costs where they can. However, there are faculty who are hesitant to switch to an open textbook for other reasons. For example, they might have doubts about the importance of saving money for students, they may perceive open education as a passing fad, or they may not be aware of the support available to them for switching textbooks. For open education advocates who understand the importance of OERs for improving learning experiences and helping students, the focus of their initiatives is on changing these faculty attitudes.

Changing someone's attitude can be very difficult. Even though attempts at doing so are sometimes successful, psychological research shows that it is often more effective to change someone's actions, rather than attempting to change their attitude (Crimmins, 2016). According to self-perception theory, people do not really have a true understanding of themselves, but, rather, infer who they are based on how they behave (Bem, 1972). Therefore, counter-intuitively, changing someone's behavior often results in that person changing their attitude in order to be consistent (Harmon-Jones, 2002). Faculty members' attitudes are difficult to change but helping 
them assign their actions to attitudes that are consistent with better learning outcomes may be more fruitful.

One tactic that takes advantage of self-perception theory is called the "foot-in-the-door technique" (Crimmins, 2016). This technique rests on the idea that "persuading people to take a small action is more feasible and, once they take the small action, their attitude begins to change, making the major persuasion possible" (Crimmins, 2016). For example, although many libraries would like to encourage faculty to consider using openly-licensed materials, it may be easier to encourage a smaller action, such as using a library-licensed ebook, trying electronic course reserves, or piloting a single, small OER in their course. Once an instructor tries changing their course content and observes the benefits of doing so-including a sense of inclusion in the campus affordability initiative - they may be more open to considering an action that was once more daunting, such as switching to an open textbook.

Another strategy for changing faculty behavior is to show gratitude to early adopters in settings where their colleagues will see it. This strategy takes advantage of a number of psychological effects, one of which is called "social proof' - evidence that an idea has value because trusted members of one's in-group have vouched for it (Cialdini, 1993). This psychological phenomenon builds on the idea that people like to identify with social peers who feel the way they themselves want to feel (Crimmins, 2016). When faculty see colleagues publicly praised and appreciated for their work of switching to more affordable course materials, they may want to feel appreciated as well. Humans strive to think of themselves positively (a phenomenon called the self-image enhancement effect), and so faculty may be interested in joining an initiative that associates them with the positive self-image that they strive to embody (Crimmins, 2016). An inclusive gratitude program also can lead to a larger number of faculty 
who consider themselves a part of the affordability initiative overall, which in turn means more opportunities for social proof.

Finally, public gratitude emphasizes certain and positive feelings, which humans prefer over feelings of uncertainty or unpredictability (Crimmins, 2016). Unfortunately, in some contexts this means that people are hesitant to take actions that have long-term benefits but are unpleasant in the short term. People are less likely to act in the face of a "delayed, uncertain, and rational reward," but may be persuaded by an "immediate, certain, and emotional reward" (Crimmins, 2016). Faculty who see their peers publicly thanked can see a clear path to positive emotional responses from their institution. And faculty who have been told that they already are contributing to an affordability initiative may begin to feel positively toward it. They may perceive themselves as part of a solution they support ideologically, even if they did not feel that way before. This can propel the momentum of an initiative forward so that it begins to feel like a campus-wide effort, rather than merely the library's pet project.

\section{Background}

Cleveland State University (CSU), located in downtown Cleveland, serves a diverse student population of approximately 17,700 students. Offering one of the most affordable tuition rates for a four-year public university in Ohio, CSU serves many first-generation and Pelleligible students. Approximately 27 percent of the CSU student population comes from a minority group; of those, two-thirds are African American. More than 1,400 CSU students are international students, and about one-third are graduate students.

CSU's Michael Schwartz Library has been active in promoting textbook affordability efforts since 2014, when it became one of the seven founding members of the Open Textbook 
Network, which as of this writing has over 1,000 campus members around the world. Since spring, 2016, the Michael Schwartz Library has been offering small Textbook Affordability Grants to help faculty adopt or adapt open educational resources or library-licensed content in courses to save students money. By fall of 201928 grants were awarded, with an estimated impact for 4,387 students. If the open textbooks adopted at CSU replaced books that cost, on average, $\$ 100$ each, then CSU students saved a cumulative total of $\$ 438,700$ from the first-year implementations of these grants alone. In addition to the Textbook Affordability Grant program, the library also partners with other departments on campus to bring in external speakers, offers an annual Textbook Hero Award, and conducts several open textbook workshops per academic year.

All of these initiatives — grants, awards, external speakers, and regular workshops — are common on other campuses, and have been successful in making open education a spotlight issue at CSU. However, with no additional funding and a desire to maintain momentum after several successful events, CSU decided to add some new outreach tactics to its efforts.

\section{Methods}

The Michael Schwartz Library has had success with programming and grant initiatives and estimates that the grant program alone has saved students more than $\$ 400,000$ since its initiation in 2016. However, grant applications have slowed, and in 2019 the OER Committee recognized that the campus needed a culture shift. This article uses Dean's definition of cultural change: "embedded shifts in routines, behaviors, values, and expectations at both individual and institutional levels" (2018). In 2019, CSU turned its efforts toward nurturing a campus culture of support, gratitude, and student learning in which open education could naturally flourish. In such 
a culture, faculty could feel that the difficult work of modifying and improving their teaching was supported, and the library could have an important role in providing that support. Based on the psychology insights described above, there were three criteria for CSU's new faculty outreach strategy:

1. It should be public. The audience for outreach efforts was faculty peers and assessors who may still perceive open education as a passing fad or "just another initiative."

2. It should be positive. It became clear early on that messages that blamed faculty or nagged them to replace their textbooks were not successful and could actually undermine the library's efforts. The focus of this campaign was engendering a sense of gratitude.

3. It should be inclusive. Although the use and creation of OERs is still heavily promoted, this campaign included any faculty who had made attempts to consider affordability when choosing course materials. This approach cast a wide net and helped those faculty identify as part of the campus affordability campaign.

CSU's initiative, which was called a "gratitude campaign," centered on highlighting and publicly praising the faculty who have been OER champions in the initial stages of the program. The library was the leader in these efforts, but by no means the only campus department involved. The CSU OER Committee, Center for eLearning, Student Government Association, Center for Instructional Technology and Distance Learning, and Center for Faculty Excellence all provided feedback and ideas.

While some strategies targeted grant and award winners exclusively, many of them included a wide variety of faculty, all of whom had demonstrated an interest in reducing textbook costs for students. Faculty on the longer list were called "affordability advocates." This affordability advocate list was generated through conversations with faculty and students, and by 
word-of-mouth from other library staff. Any faculty member who had participated in an open education event on campus was also added to the list. Faculty from a wide variety of departments, using a variety of methods to reduce textbook costs, were considered affordability advocates. Listed faculty included those who used library-licensed content, openly-licensed content, free material, and, in some cases, no required textbook at all. At CSU, the goal is to prioritize the use of open materials, not just saving students money. However, faculty who are already thinking about textbook costs might become strong allies in the move toward open education. Maintaining an affordability advocates list helps reach a greater number of faculty.

One element of the gratitude campaign was giving key faculty champions a voice in an OER advocacy video that was created in collaboration with the CSU Center for Technology and Distance Learning (CITDL). The designers of the video decided early on that, instead of highlighting student voices, the video would be an opportunity to feature faculty champions and show gratitude for their willingness to embrace CSU's initiative. The video features interviews of several faculty who received Textbook Affordability Grants, as well as an administrator who supported faculty grant-winners, and a faculty member who did not win a grant but was a vocal proponent of textbook affordability. Video creation took hours, even though the resulting video was only seven minutes. However, the result was an extremely valuable tool, both for highlighting the library's affordability efforts, and for publicly thanking faculty colleagues who had taken action to reduce textbook costs. Drawing on the psychology of persuasion, the video relied on social proof, and it provided certain and positive messaging from faculty colleagues. (A link to the video is here: https://youtu.be/filJsHr-AFk).

The library also received feedback that grant winners were struggling to find ways of gaining credit during the promotion and tenure process for their textbook affordability efforts. To 
address this need, the library modified an openly-licensed thank-you letter developed by the University of Alaska Southeast, and asked CSU's Provost if he would sign letters for all grant winners. He agreed to do so, providing grant winners with important evidence of the value of OERs to the university and to student learning. While this letter would not be publicly displayed, members of promotion and tenure committees would see the Provost's support for their colleagues' efforts when they viewed this letter in the dossiers under review, providing some valuable social proof. The letter, openly licensed, may be found in Appendix 1.

The CSU librarians also wanted to create flyers, monitor displays, and other marketing material showing the faces of grant winners and encouraging others to apply for the grant. However, when faculty grant winners were asked to provide a photo for marketing purposes, many were not able to provide a high-resolution, professional photo. The OER Committee decided to hold several photoshoots, with photos taken by an amateur photographer on the OER Committee and instructional designer in the Center for eLearning. All of the winners were ultimately given full permission to use the professional photographs in other contexts, which allowed the library to extend thanks to them without spending any additional funds. It also employed the foot-in-the-door technique by making a small ask (for faculty to have their photograph taken), and then moving to a larger one (for faculty to have their photograph featured in library marketing).

The CSU OER Committee is fortunate to have one SGA representative each academic year, usually selected by the SGA president. In 2019, the OER Committee was able to organize a meeting between the SGA representative, the author of the present article, and Nicole Finkbeiner, who came to CSU for a day to meet with various groups and committees about open textbook adoption. Finkbeiner's advice was to make sure that CSU's student open textbook 
efforts remained positive; she had learned through experience that negative campaigns (like the \#textbookbroke campaign) could alienate some faculty and make them defensive. Based on her advice, and with considerable help from the library's marketing staff, the SGA representative and the author of the present article created large thank-you cards, signed by students, for all faculty affordability advocates. Because most students are still unclear about what an open textbook is and may even be unaware that their professor is using one, it seemed easiest to have SGA members themselves sign the cards on behalf of the student body. SGA had, fortunately, heard from an OER Committee representative several times about open textbooks, and they were eager to help.

The cards were incorporated into a virtual poster that was displayed in May, 2020 at the Provost's Teaching Summit, an annual event that celebrates teaching excellence and features an award ceremony. Many faculty who prioritize pedagogical mastery attend this event, making it a great opportunity to publicly praise affordability advocates. This approach was positive and affirming, providing a clear path to the positive faculty-student relationship that many faculty desire. Images of the cards can be found in Appendix 2.

Because the gratitude campaign relied on social proof, the library wanted to thank CSU's affordability advocates publicly and, importantly, in a manner that would attract the attention of their colleagues. The library's marketing staff member decided to create door hangers for all of our affordability advocates' office doors. These door hangers serve as a public reminder to other faculty of the importance CSU assigns to considerations of textbook cost, and they may refresh a faculty member's memory at a critical juncture, such as when they are choosing a new course textbook. Because the library had not directly worked with many of the faculty on their affordability efforts, the door hanger project also served to reframe the actions of those faculty as 
part of our initiative. Some of the faculty may not have identified themselves as part of the affordability initiative on campus, but once their actions were reframed, their attitude toward the program was likely to follow. The design of the door hanger can be found in Appendix 3 .

For Textbook Affordability grant recipients who had successfully completed their projects, a visit to their office door was used as an opportunity to celebrate their contribution on social media. Library staff planned to bring those faculty a "goody bag" of library swag, complete with information about upcoming campus open education events. Faculty were contacted in advance to ensure they would be in their offices in order to obtain photos of them receiving their goody bags for posting on social media, but most faculty were not available at the same time. Instead, the faculty members were invited to come to the library to pick up the goody bag at their own convenience. During each faculty member's visit, a library staff member took a photo of the faculty member with the large student-signed cards to emphasize how grateful students are for faculty contributions to affordability efforts. For one of the visits, two student representatives from SGA were present for the photo and to personally thank the faculty member.

The use of social media to publicly display the hand-off of the goody bag provided social proof for faculty seeing their admired colleagues being thanked for their important efforts. The goody bag initiative was also completely positive, as it did not invoke textbook costs or single out faculty who did not choose to use an open textbook for whatever reason. The uplifting photos merely provided examples of CSU's support and commitment toward affordability efforts, and a clear path to gratitude. Photos posted on social media can be found in Appendix 4.

\section{Results}


As a result of this campaign, 58 faculty from 26 departments received direct outreach from the library, 33 of whom were not Textbook Affordability Grant winners. Four faculty were featured on the library's social media, and 15 faculty received a library goody bag. Before this campaign, most outreach to faculty about open education came in the form of email invitations to apply for a grant or attend a workshop. Direct, targeted library outreach to faculty about textbook affordability clearly increased as a result of the campaign. The outreach was more public (it was more visible to other faculty), positive (it did not ask faculty to do anything or reiterate the issue of textbook costs), and inclusive (it targeted many more faculty than previous outreach).

Unfortunately, the goal of the gratitude campaign — increased engagement from faculty in our affordability efforts - is very challenging to assess. Some anecdotal feedback from faculty about the campaign included comments like, "Thank you so much! Who would refuse a gift under these lovely circumstances?", "That's very nice of you all! ... Thanks so much for the goody bag!", "I think faculty should also be thanking you and your team for the great support and encouragement throughout the process", and "That's so nice for you all to do that!" The campaign's social media posts received engagement from four individuals and were shared two times. Overall, faculty who participated were very positive about the experience.

Beyond just engaging faculty champions, an important objective of the initiative was to increase engagement by faculty who had not been previously involved CSU's affordability program. It is not possible to fully isolate the effect of our campaign, and the influence of the COVID-19 pandemic may have been significant; however, the number of faculty Affordable Learning Grant applications received in fall of 2019 (before the campaign) was three, and the number received in spring of 2020 (after the campaign) jumped to twelve, the most the program had ever received in one semester. One of the spring applicants was a previous winner who had 
lost touch with the library for several years, but who had a very positive reaction to the gratitude campaign. Ten other applicants had never been involved in CSU's affordability initiative before as a grant or award winner, so the applications represented an influx of new faculty advocates to serve as models for their colleagues.

While it may be difficult to link the gratitude campaign with increased engagement in the affordability program, positive faculty feedback, an increase in grant applications, and engagement from a fresh group of faculty were the desired objectives when the campaign began. Based on the first, positive experience, the library will continue to deliver the campaign, as well as track engagement with affordability efforts as gratitude campaign activities are reintroduced in future semesters.

\section{Discussion}

Despite the initial success of the gratitude campaign, many of the typical challenges of promoting open education remain, and efforts to change campus culture will, of course, require continued efforts. When the challenges that faculty face include a lack of open options, lack of ancillaries (accompanying material for a textbook, such as test banks), or a deep commitment to their current, commercial textbook, alternative strategies will need to be employed to support open education adoption. As Ivie and Ellis (2018) point out, "OER advocacy requires consistent and comprehensive effort."

In addition, not everything went smoothly in implementing the campaign. There were challenges in agreeing how best to give thanks without overwhelming or alienating the faculty, and there were difficulties in working with stakeholders who were not able to help throughout the entirety of the campaign (e.g., the SGA representative left mid-campaign for a job). In the future, instead of expecting faculty to be available to receive their goody bags all at the same 
time, the library will schedule times for faculty to pick them up when it is most convenient. Future efforts will also need to consist of mostly or fully online outreach activities, as most of our faculty will not be on campus as much as usual due to the COVID-19 pandemic. Despite these challenges, all parties involved learned much from the process, and the library hopes to offer an even more smoothly implemented and successful program again in the future.

Even librarians who are just beginning their affordability programs will encounter faculty who have been worried about textbook costs and helping students cope, perhaps for years. These early affordability champions are an ideal audience for a gratitude campaign. Below are some potential applications of this case study for those considering reaching out to thank faculty:

1. Maintain a list of faculty who are making efforts to save students money. It can be very challenging to get a sense of what course materials faculty are actually using in their classrooms. If faculty or students share information about specific efforts to reduce textbook costs, keep a running list of these individuals. Not only can these affordability advocates make great gratitude campaign recipients, but having their names listed allows them to be specifically invited to participate in other outreach events and efforts.

2. Get help from many stakeholders. Likely there are many people on campus who care about textbook affordability. Try to include them in the planning for a gratitude campaign — it can be a positive experience for them as well. This can be an especially good opportunity to encourage student advocacy, since gratitude campaigns are so positive in nature.

\section{Consider how to scale up gratitude projects without adding a lot of time and effort.} Plan ahead for future efforts, especially when funding is tight. Keep messages generic so items can be reused and create extra materials that can be used in the future. 
4. Be creative. A hallmark of CSU's gratitude campaign was that it extended thanks to faculty when there was no additional funding to offer them. Consider what skills colleagues have and employ them to show gratitude. For example, many of CSU's grant winners did not have professional photos, so the campaign was able to provide that added value for them. Thinking of these positive outreach strategies may require some creativity.

5. Follow up with actions for faculty who are now part of the effort. Unfortunately, implementing a gratitude campaign is only the beginning. After helping faculty feel a sense of belonging in an affordability program, reach out to them and make a specific ask, whether that is to pilot an open textbook, participate in a grant program, or attend an open textbook workshop. Do not allow your campaign to lose momentum! Many of the psychology-based strategies of the gratitude campaign could be used to improve any library outreach effort. Reframing faculty behavior rather than focusing on changing attitudes, making small asks that build up to larger ones, providing opportunities for faculty to demonstrate social proof, and keeping messaging certain and positive can help improve the results of a library outreach program without requiring additional funding.

At a differently-sized institution, the gratitude campaign strategy could be adapted to scale up or down, as appropriate. Regardless of the number of faculty on a particular campus, a gratitude campaign that publicly thanks faculty, remains positive, and includes as many affordability advocates as possible can contribute to a campus culture change. Any campus initiative will need to be catered to the specific campus that is being targeted, but these ideas can help a library begin its campaign on the right foot.

\section{Conclusion}


While textbook affordability grant programs and awards have allowed many campuses to make great progress, changing the culture of an institution requires a variety of strategies and persistent, ongoing work. A gratitude campaign is one strategy that does not require additional financial resources and can take advantage of social proof and other psychological heuristics. Showing thanks for the risks and effort that faculty are willing to assume for the benefit of their students is a positive way to widen the net of stakeholders in an open education initiative. Combined with other faculty outreach activities, a gratitude campaign can help libraries build a coalition, strengthen partnerships, and cultivate a positive campus culture in which open education can thrive. 


\section{References}

Ameil, T. (2012), "Identifying barriers to the remix of translated open educational resources," International Review of Research in Open and Distance Learning, Vol. 14, No. 1, available at: http://www.irrodl.org/index.php/irrodl/article/view/1351/2428.

Bay View Analytics. (2019), Inflection Point: Educational Resources in U.S. Higher Education, available at: http://www.onlinelearningsurvey.com/reports/2019inflectionpoint.pdf.

Bem, D. (1972), "Self-perception theory", Advances in Experimental Social Psychology, Vol. 6 No. 1, pp. 1-62, available at: http://healthyinfluence.com/wordpress/wpcontent/uploads/2011/05/SP-Theory-Bem-Advances.pdf (accessed 15 February 2020).

Cassidy, T., Reinauer, O. and Walz, A.R. (2015), "In the highways and hedges: library support for OER adoption efforts at higher education institutions across Virginia", in Where do we go from here? Charleston Conference Proceedings 2015, Purdue University Press, available at: https://doi.org/10.5703/1288284316313.

Celik, O. and Peck, R. (2016), "If you expand, they will come: textbook affordability through expansion of course reserves: the case of UCLA library's course reserves via strategic partnership with the campus independent bookstore”, Technical Services Quarterly, Vol. 33 No. 3, pp. 268-278, available at: https://doi.org/10.1080/07317131.2016.1169788.

Cialdini, R.B. (1993), Influence: The Psychology of Persuasion, Collins, New York, NY.

Colvard, N.B., Watson, C.E. and Park, H. (2018), "The impact of open educational resources on various student success metrics", International Journal of Teaching and Learning in Higher Education, Vol. 30 No. 2, pp. 262-276, available at: https://eric.ed.gov/?id=EJ1184998. 
Crimmins, J.C. (2016), Seven Secrets of Persuasion: Leading-edge Neuromarketing Techniques to Influence Anyone, Career Press, Wayne, NJ.

Davis, E., Cochran, D., Fagerheim, B. and Thoms, B. (2016), “Enhancing teaching and learning: libraries and open educational resources in the classroom", Public Services Quarterly, Vol. 12 No. 1, pp. 22-35, available at: https://doi.org/10.1080/15228959.2015.1108893.

Dean, K.N. (2018), "From conversation to cultural change: strategies for connecting with students and faculty to promote OER adoption”, in Wesolek, A., Lashley, J. and Langley, A. (Eds.), OER: A Field Guide for Academic Librarians, Pacific University Press, Forest Grove, OR, pp. 253-269, available at: https://commons.pacificu.edu/cgi/viewcontent.cgi?article=1003\&context=pup

Emory Scholarly Communications Office. (n.d.), "Emory’s Open Education Initiative”, available at: https://sco.library.emory.edu/oer/emory-initiative.html (accessed 15 February 2020).

Florida Virtual Campus. (2019), “2018 Student Textbook and Course Materials Survey”, available at: https://dlss.flvc.org/documents/210036/1314923/2018+Student+Textbook+and+Course+ Materials+Survey+Report+--+FINAL+VERSION+--+20190308.pdf/07478d85-89c23742-209a-9cc5df8cd7ea (accessed 15 February 2020).

Harmon-Jones, E. (2002), “A cognitive dissonance theory perspective on persuasion”, in Dillard, J.P. and Pfau, M. (Eds.), The Persuasion Handbook: Developments in Theory and Practice, Sage Publications, Inc., Thousand Oaks, CA, pp. 99-116, available at: http://www.socialemotiveneuroscience.org/pubs/hj2002_persuasion.pdf (accessed 15 February 2020). 
Ivie, D. and Ellis, C. (2018), “Advancing access for first-generation college students: OER advocacy at UT San Antonio", in Wesolek, A., Lashley, J. and Langley, A. (Eds.), OER: A Field Guide for Academic Librarians, Pacific University Press, Forest Grove, OR, pp. 213-231, available at: https://commons.pacificu.edu/cgi/viewcontent.cgi?article=1003\&context=pup.

Jensen, K. (2018), "Student feedback on affordable content in the classroom at the University of Minnesota", In Jensen, K. and Nackerud, S. (Eds.), The Evolution of Affordable Content Efforts in the Higher Education Environment: Programs, Case Studies, and Examples, University of Minnesota Libraries Publishing, available at: https://open.lib.umn.edu/affordablecontent/chapter/student-feedback-on-affordablecontent-in-the-classroom-at-the-university-of-minnesota/.

Jensen, K. and West, Q. (2015), “Open educational resources and the higher education environment: a leadership opportunity for libraries", College \& Research Libraries News, Vol. 76 No. 4, pp. 215-218, available at:

https://crln.acrl.org/index.php/crlnews/article/view/9298/10384.

Lieberman, M. (2018), "The truth (about OER) is out there," Inside Higher Ed, available at: https://www.insidehighered.com/digital-learning/article/2018/01/10/finding-oer-remainschallenging-solutions-abound.

Martin, R. (2010), "Finding free and open access resources: a value-added service for patrons", Journal of Interlibrary Loan, Document Delivery \& Electronic Reserves, Vol. 20 No. 3, pp. 189-200, available at: https://doi.org/10.1080/1072303X.2010.491022.

Mitchell, C. and Chu, M. (2014), “Open education resources: the new paradigm in academic libraries", Journal of Library Innovation, Vol. 5 No. 1, pp. 13-29, available at: 
http://proxy.ulib.csuohio.edu:2050/login?url=http://search.ebscohost.com/login.aspx?dire

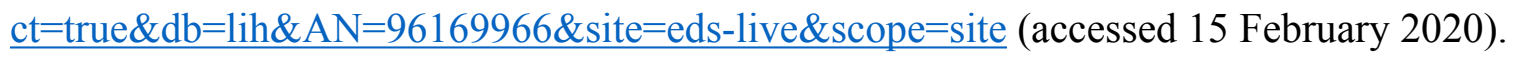
Nasccimbeni, F. and Burgos, D. (2016), "In search for the open educator: Proposal of a definition and framework to increase openness adoption among university educators," International Review of Research in Open and Distributed Learning, Vol. 17, No. 6, available at: doi: https://doi.org/10.19173/irrodl.v17i6.2736.

Okamoto, K. (2013), “Making higher education more affordable, one course reading at a time: academic libraries as key advocates for open access textbooks and educational resources", Public Services Quarterly, Vol. 9 No. 4, pp. 267-283, available at: https://doi.org/10.1080/15228959.2013.842397.

Michael Paskevicius, (2017), "Conceptualizing open educational practices through the lens of constructive alignment," Open Praxis, Vol. 9, No. 2, available at https://openpraxis.org/ openprax/index.php/OpenPraxis/article/view/519

Pitcher, K. (2014), "Library publishing of open textbooks: The Open SUNY Textbooks Program", Against the Grain, Vol. 26 No. 5, available at: https://doi.org/10.7771/2380176X.6844.

Popken, B. (2015, August 6), "College textbook prices have risen 1,041 percent since 1977”, NBC News, available at: https://www.nbcnews.com/feature/freshman-year/collegetextbook-prices-have-risen-812-percent-1978-n399926 (accessed 15 February 2020).

Rigling, L. and Cross, W. (2018), "Getting to know you: how we turned community knowledge into open advocacy," in Wesolek, A., Lashley, J. and Langley, A. (Eds.), OER: A Field Guide for Academic Librarians, Pacific University Press, Forest Grove, OR, pp. 193-211, 
available at:

$\underline{\text { https://commons.pacificu.edu/cgi/viewcontent.cgi?article=1003\&context=pup }}$

Salem, J.A. (2017), “Open pathways to student success: academic library partnerships for open educational resource and affordable course content creation and adoption", The Journal of Academic Librarianship, Vol. 43 No. 1, pp. 34-38, available at: https://doi.org/10.1016/j.acalib.2016.10.003.

Smith, J. (2018), "Seeking alternatives to high-cost textbooks: six tears of the Open Education Initiative at the University of Massachusetts Amherst", in Wesolek, A., Lashley, J. and Langley, A. (Eds.), OER: A Field Guide for Academic Librarians, Pacific University Press, Forest Grove, OR, pp. 333-339, available at: https://commons. pacificu.edu/cgi/viewcontent.cgi?article=1003\&context=pup.

Sutton, S.C. and Chadwell, F.A. (2014), “Open textbooks at Oregon State University: a case study of new opportunities for academic libraries and university presses", Journal of Librarianship \& Scholarly Communication, Vol. 2 No. 4, pp. 34-48, available at: https://doi.org/10.7710/2162-3309.1174.

Thompson, S., Cross, W., Rigling, L. and Vickery, J. (2017), "Data-informed open education advocacy: a new approach to saving students money and backaches", Journal of Access Services, Vol. 14 No. 3, pp. 118-125, available at: https://doi.org/10.1080/15367967.2017.1333911.

U.S. Advisory Committee on Student Financial Assistance. (2006), "Mortgaging our future: how financial barriers to college undercut America's global competitiveness", available at: https://files.eric.ed.gov/fulltext/ED529499.pdf. 
Wiley, D. (n.d.), Defining the "open" in open content and open educational resources, available at: http://opencontent.org/definition/. 
Appendix 1. Provost Email

TO: Textbook Affordability Grant Recipient

FROM: OER Committee, Provost's Office

RE: Recognizing Contributions to Open Education \& Affordable Course Materials, 2019

Dear X,

Thank you for your efforts to use Open Educational Resources (OERs), free content, or library licensed materials as a substitute for commercial materials in your 2019 course(s). Increasing the use of OERs and other free content aligns closely with Cleveland State University's Strategic Plan, and it benefits our overall goal to improve student achievement and retention. We recognize your use of OER or affordable course materials as a form of academic leadership that advances innovation in teaching and learning with effects beyond your classroom.

Data shows that contributions like yours result in significant positive impacts for student learning.

- The cost of traditional textbooks can be a barrier for students. ${ }^{1}$

- Studies show using OER produces equal or improved student learning outcomes compared to traditional textbooks. ${ }^{2}$

- Global adoption of OER has saved students \$1 billion since 2013 (\$900M in US \& CA higher education). ${ }^{3}$

Your 2019 adoption of BOOK/RESOURCE TITLE (OER/library content) as a required text for COURSE \# saved your students $\$ X$ (based on the replacement of a $\$ 100$ commercial textbook).

If you receive student course comments related to your selection of affordable course materials, we encourage you to share them with us. We also hope you will include this letter in your promotion and tenure file as evidence of innovative teaching that supports student success at CSU.

Sincerely,

"OER Champion Recognition Letter template" by University of Alaska Southeast and modified by Cleveland State University is licensed under a Creative Commons Attribution 4.0 International License.

1. https://studentpirgs.org/sites/student/files/reports/National\%20-\%20COVERING\%20THE\%20COST.pdf

2. https://openedgroup.org/review

3. https://sparcopen.org/news/2018/1-billion-in-savings-through-open-educational-resources/ 
Appendix 2. Student Thank You Cards

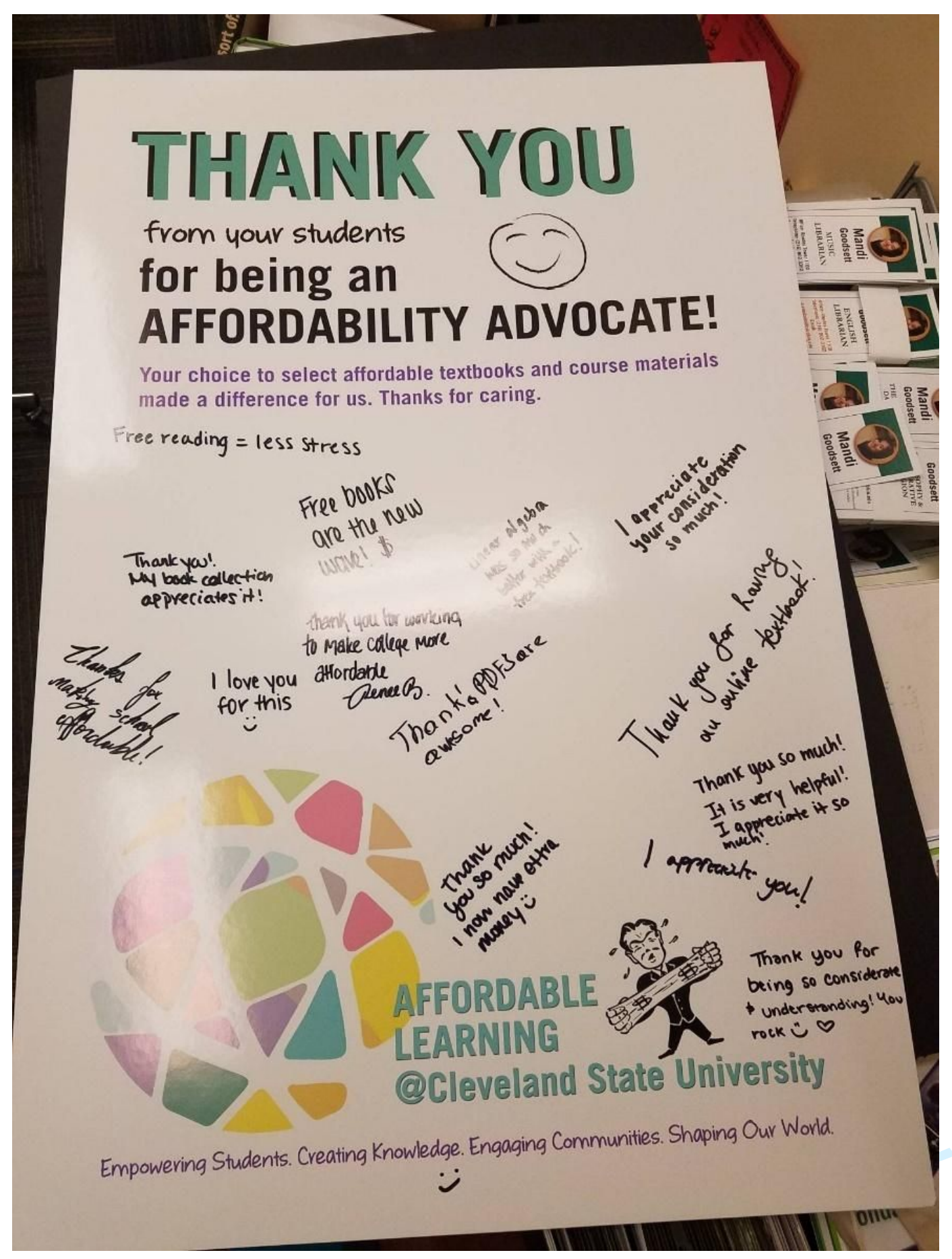

Figure 1: Student Gratitude Thank Poster \#1 
THANK YOU

from your students for being an AFFORDABILITY ADVOCATE!

Your choice to select affordable textbooks and course materials made a difference for us. Thanks for caring.

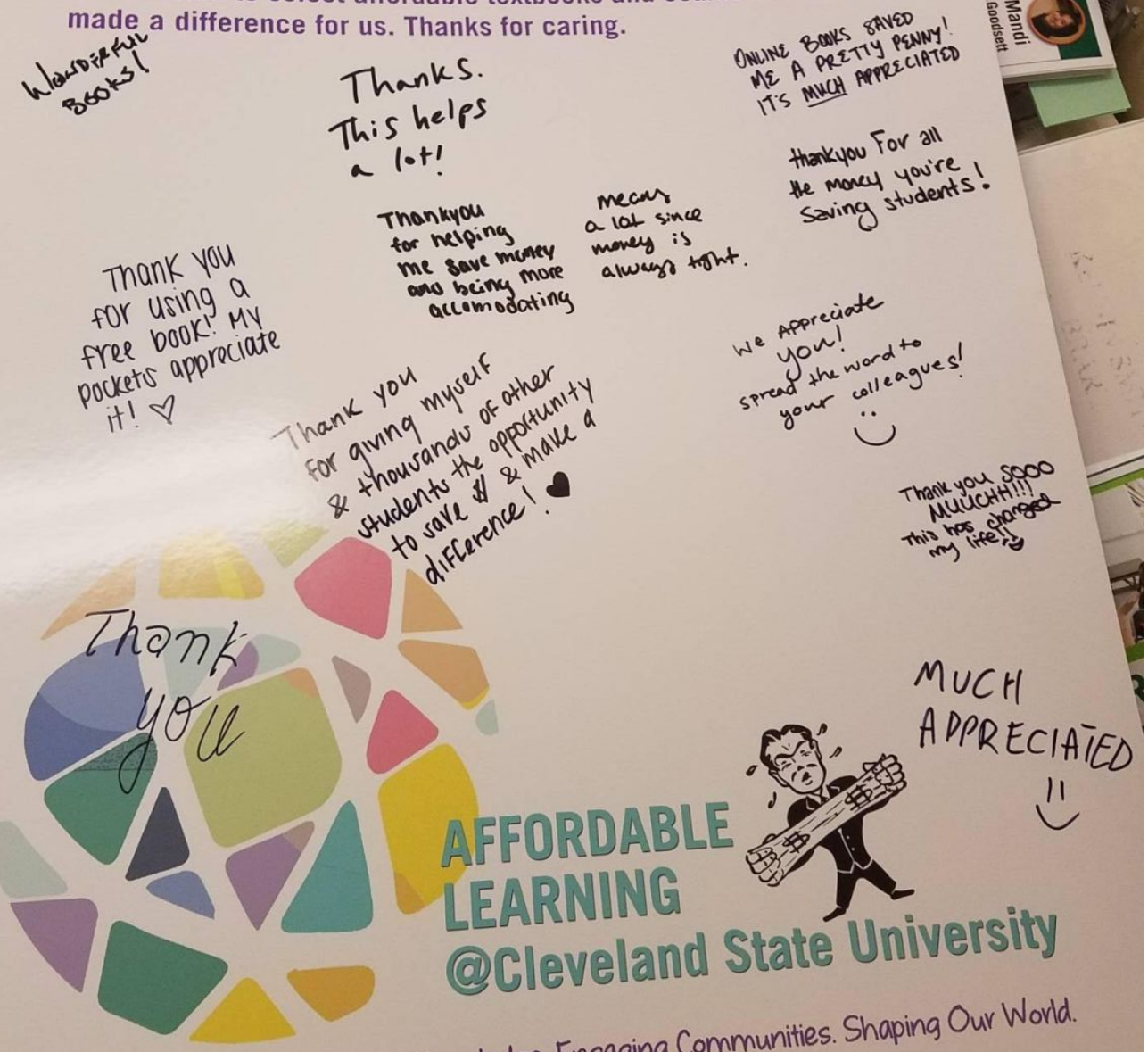

Figure 2: Student Gratitude,Thank Pestiergowledge. Engaging Communities. Shaping Our World. 


\section{Appendix 3. Door Hanger Design}

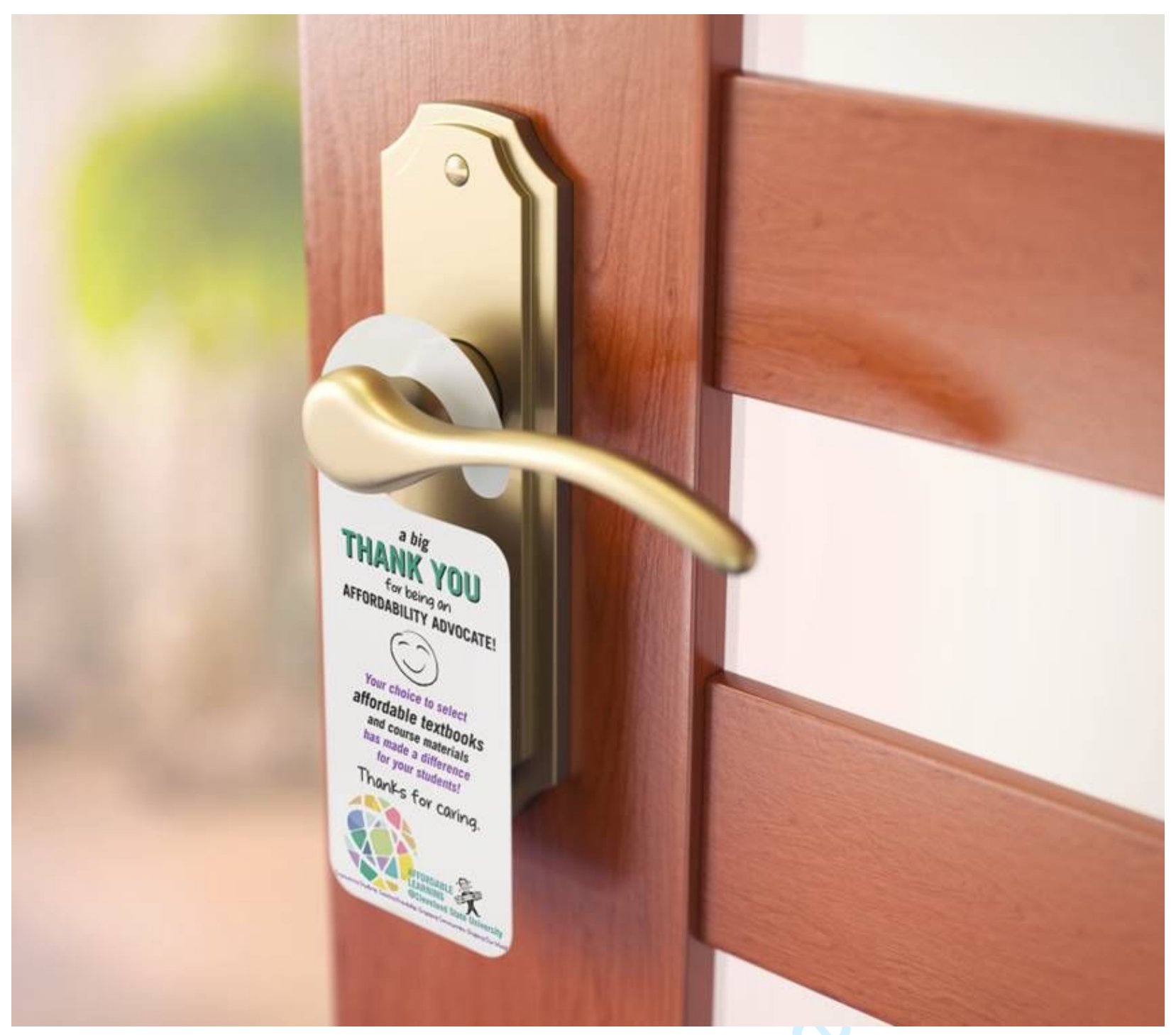

Figure 3: Door hanger design in context 

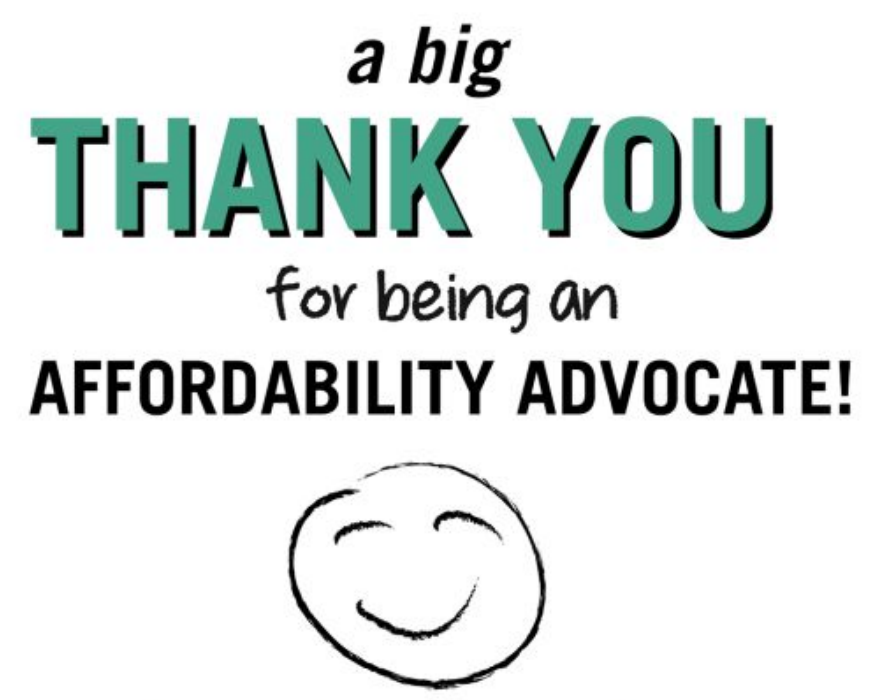

Your choice to select affordable textbooks and course materials has made a difference for your students!

Thanks for caring.

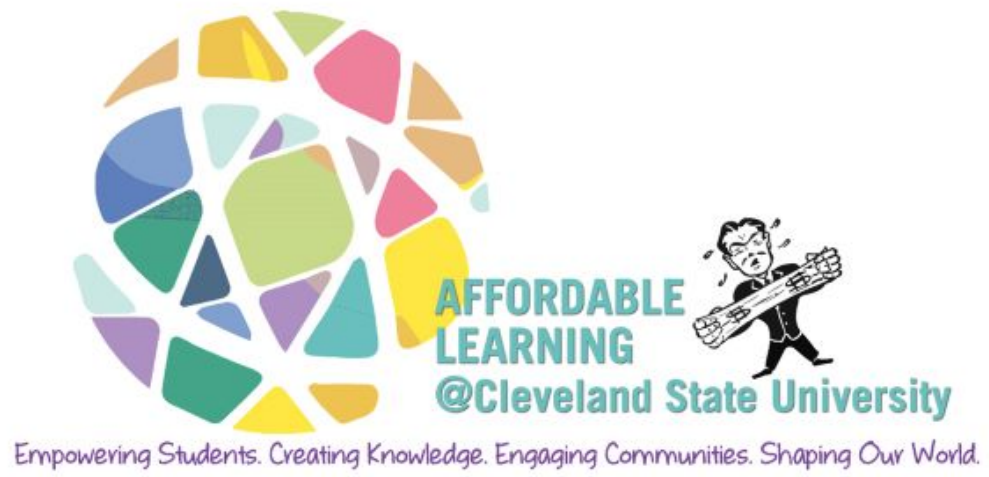

다)(i) (2) (2)

Figure 4: Thank you door hanger design 
Appendix 4. Goody Bag Delivery Social Media Posts

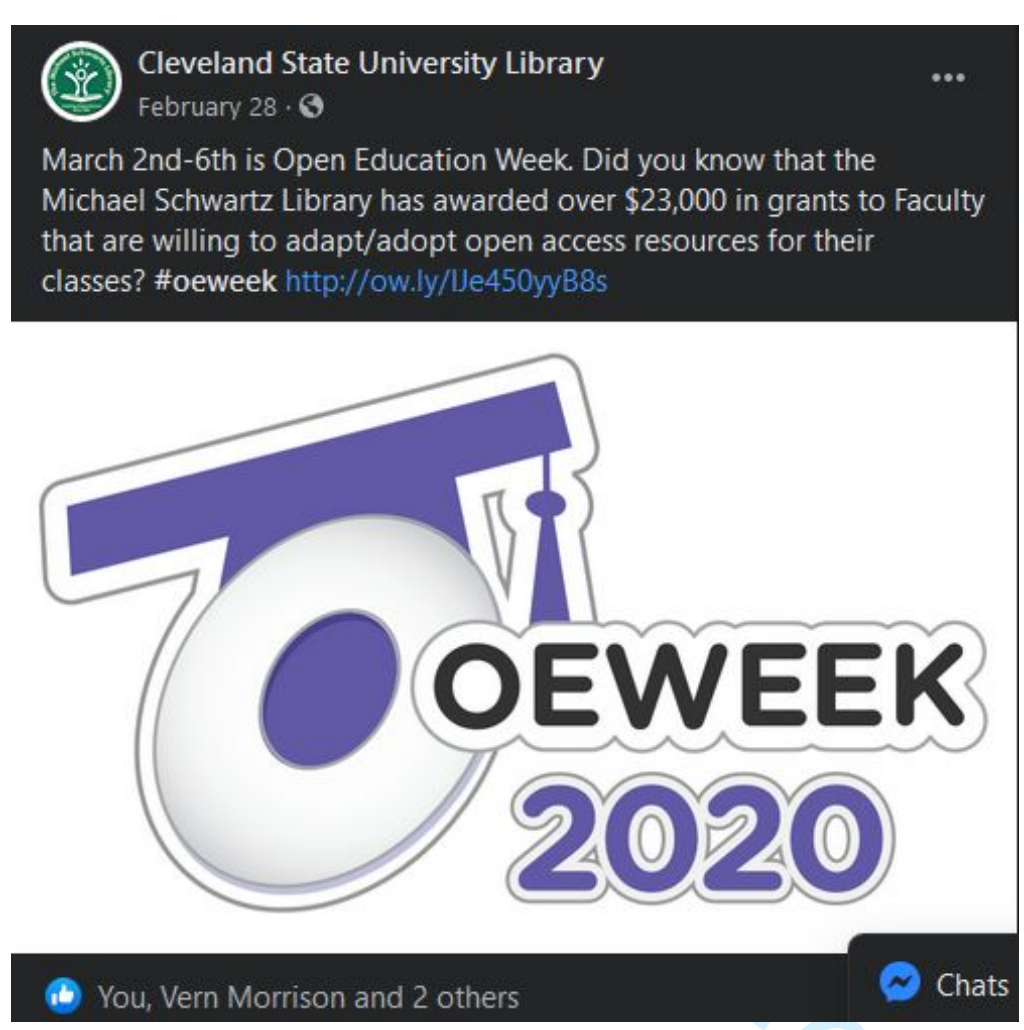

March 2nd-6th is Open Education Week. Today, we would like to recognize Browne Lewis, Professor in the College of Law, for using open educational resources in her LAW 609 class \#oeweek \#AffordabilityAdvocate

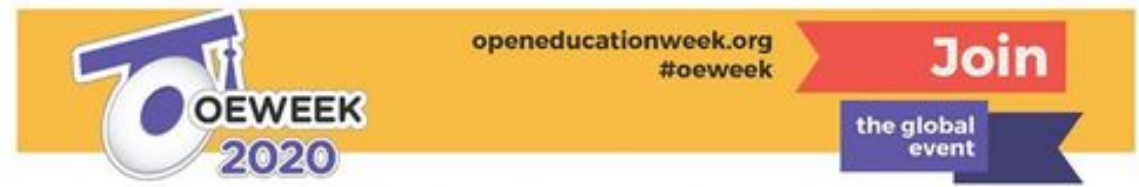

\section{Celebrating Faculty members that have} adopted/adapted open educational resources

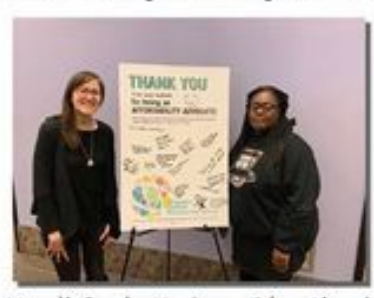

Mandi Goodsett, Open Educational
Resources Librarian Resources Librarian $(L)$ with
Thank you

Professor Lewis

for saving your

students over

$\$ 10,000 /$ year 


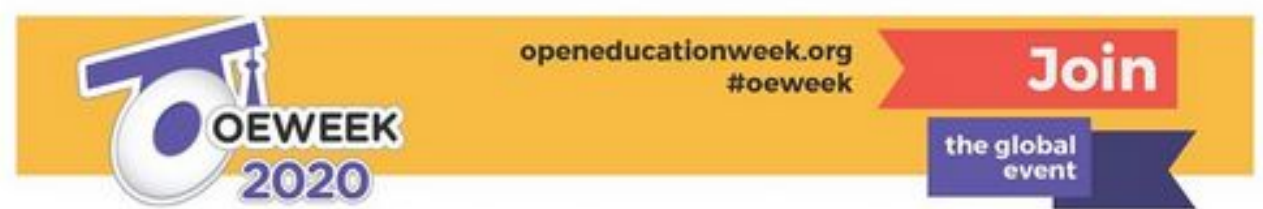

\section{Celebrating Faculty members that have} adopted/adapted open educational resources

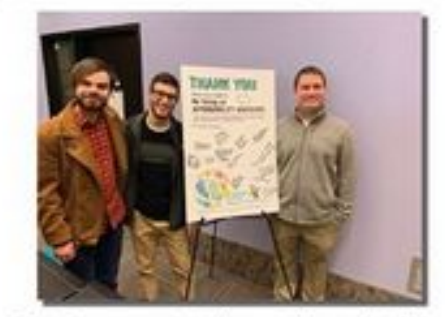

Thank you

Professor Ryan

for saving your

students over

$\$ 22,000 /$ year

SGA Representatives, Jake and Atia (L) with Shawn Ryan (R) 